\title{
MODELAGEM MATEMÁTICA DA CONCENTRAÇÃO DE FÓSFORO: UMA FERRAMENTA PARA A GESTÃO DOS RECURSOS HÍDRICOS
}

\author{
MATHEMATICAL MODELING OF PHOSPHORUS \\ CONCENTRATION: A TOOL FOR WATER RESOURCES \\ MANAGEMENT
}

\section{Camila Pereira Montovani ${ }^{1}$; Elaine Cristina Catapani Poletti ${ }^{2}$}

\author{
${ }^{1}$ Mestra em Tecnologia, Universidade Estadual de Campinas (UNICAMP). E-mail: \\ camilamontovani@yahoo.com.br \\ ${ }^{2}$ Professora Doutora da Faculdade de Tecnologia (FT) da Universidade Estadual de \\ Campinas (UNICAMP). E-mail: elainec@ ft.unicamp.br
}

\begin{abstract}
RESUMO
A água é um bem essencial à vida, dessa forma é imprescindível a garantia de sua qualidade para, dentre outras razões, a sobrevivência dos seres vivos. Hoje em dia, com a amplitude e o desenvolvimento das atividades antrópicas, é importante que rios, reservatórios e mananciais estejam com características físicas, químicas e biológicas dentro dos padrões estabelecidos pelos órgãos governamentais, de acordo com a classe a que se destinam. Com o intuito de se desenvolver uma ferramenta de suporte à gestão de recursos hídricos para análises de comportamento de poluentes, realizou-se uma modelagem da concentração do componente fósforo baseado em instrumentos matemáticos e computacionais, num manancial de abastecimento público. Os resultados obtidos apresentam o comportamento evolutivo do poluente e possibilitam a geração de cenários e a tomada de decisões com vistas a ações preventivas ou de remediação acerca de um componente que, em excesso, interfere na qualidade das águas devido, principalmente, ao processo de eutrofização que compromete toda a biota local.
\end{abstract}

Palavras-chave: Sistemas de reservatórios. Eutrofização. Modelagem matemática. Simulação computacional.

\begin{abstract}
Water is a key asset to life, it is imperative to guarantee their quality, among other reasons, to the survival of living beings. Nowadays, with the range of the anthropogenic activities, it is important that rivers, reservoirs and springs are with physical, chemical and biological character according to the standards established by government, according to the class as intended. With the purpose to develop a tool to support the management of water resources for analysis of behavior pollutants, we carried out a phosphorus modeling based on mathematical and computational tools, in a public water supply source. The results feature the pollutant evolutionary behavior, allowing to analyze scenarios and make decisions with a view to preventive or remedial about a component that, in excess, interfere with water quality, mainly, in the eutrophication process that undertakes all the local biota.
\end{abstract}

Keywords: Reservoir systems. Eutrophication. Mathematical modeling. Computer simulation. 


\section{INTRODUÇÃO}

A água é essencial à vida e à manutenção dos ciclos ecológicos, porém necessita apresentarse livre de contaminantes ou organismos patogênicos para suprir as necessidades vitais dos seres vivos. O desenvolvimento humano, entretanto, tem elevado acentuadamente os casos de depreciação da qualidade das águas de rios, reservatórios e outros mananciais, cuja poluição é caracterizada por alterações físicas, químicas e biológicas do meio (MARINS et al., 2007; ALEXANDRE et al., 2010; BEGHELLI et al., 2012; DELLAMATRICE et al., 2012).

Os corpos de água, ao longo dos anos, vêm sofrendo com a carga de aporte de poluentes que são descartados em volumes proporcionais ao desenvolvimento da economia e da melhora da qualidade de vida, decorrentes do acelerado crescimento urbano, industrial e agrícola. Dentre os problemas de impacto ambiental nos recursos aquáticos, os lançamentos de efluentes domésticos e industriais, acentuados pelo fenômeno à deriva dos processos de lixiviação do solo que contêm agroquímicos, são responsáveis pelas elevadas concentrações de fósforo que provocam grande desequilíbrio do ecossistema.

A presença em excesso de fósforo na água acentua a proliferação de algas no meio e provoca a eutrofização que eleva os níveis de toxicidade, reduz a transparência da água e, consequentemente, altera a biodiversidade. Assim sendo, o componente pode ser utilizado como um indicador da qualidade da água (MANSOR et al, 2006; MARINS et al., 2007; ANDRADE et al., 2012; BEGHELLI, 2012).

\section{1. Água: Um Recurso Vulnerável}

A disponibilidade de água é de grande importância para a manutenção dos ciclos naturais e da sobrevivência no planeta Terra, entretanto, além da disponibilidade, a qualidade também é de extrema importância. Como num ciclo, a qualidade e a quantidade de água são bases para o desenvolvimento vital e econômico em uma região, que voltam a contribuir para a qualidade e a quantidade, usualmente, com efeitos negativos predominantes (POLETTI, 2009).

No último século, o desenvolvimento urbano e industrial demandou uma quantidade crescente e acelerada do recurso. Rios, lagos, lagoas, praias, baías e reservatórios sofrem ao serem submetidos a alterações bruscas sejam elas naturais ou devido às atividades humanas tornando cada vez mais difícil atingir os padrões de potabilidade, inclusive pela precariedade do sistema de saneamento básico dos municípios (FIGUEIRÊDO et al., 2007).

Os ecossistemas aquáticos são de extrema importância para a manutenção de diversas espécies de animais e de plantas, entretanto, são ameaçados pela eutrofização, considerada um dos maiores problemas e, o mais grave deste sistema, prejudicando a vida aquática, a captação e a distribuição de água nos municípios (MARINS et al., 2007; JORGENSEN et al., 2012).

Os recursos aquáticos que mais sofrem com os problemas de eutrofização são os sistemas de represamento das águas. Os corpos d'água têm suas águas represadas com o objetivo de garantir o abastecimento público regular, a geração de energia elétrica em uma região, a irrigação, a prevenção de enchentes a até mesmo a recreação. De modo geral, os reservatórios constituem um ecossistema artificial de acumulação e passagem de água, cuja vazão é passível de controle. Estes sistemas são dimensionados de modo que os níveis da água sejam alterados rapidamente de acordo com a necessidade (BUFON e LANDIN, 2007; TANIWAKI et al., 2011).

As águas represadas possuem características próprias de acordo com os fatores naturais da região em que se localizam os corpos aquáticos. No estado de São Paulo os parâmetros de qualidade são determinados pela Companhia Ambiental do Estado de São Paulo (CETESB) e variam de acordo com o enquadramento das classes e a finalidade de uso das águas (FRAGOSO JÚNIOR et al., 2007; JORGENSEN et al., 2012). 
Os principais impactos da construção de um reservatório são: mudanças no sistema ecológico do rio, redução da biodiversidade e degradação da qualidade da água. Dentre os agravantes presentes nos reservatórios, tem-se o acúmulo de nutrientes ricos em fósforo e nitrogênio, principais responsáveis pelo fenômeno denominado eutrofização, que é provocado pelo aumento excessivo de algas aquáticas. O nível de eutrofização é determinado através da concentração de clorofila $a$ que é o parâmetro utilizado como indicador da biomassa fitoplanctônica (FRAGOSO JÚNIOR et al., 2007; JORGENSEN et al., 2012).

A densa camada de alga que se instaura dificulta a entrada de luz, influenciando a quantidade de oxigênio no meio, pela redução da taxa fotossintética. A consequência da diminuição do oxigênio é um déficit para a manutenção dos organismos aquáticos que sem condições de suprimento morrem, aumentando o teor de matéria orgânica e a liberação de toxinas no meio. Além disso, fatores como temperatura, radiação solar, turbidez e profundidade são alguns dos fatores que influenciam a taxa de produtividade da vegetação aquática. Desta forma, constata-se que os reservatórios formam um sistema ecológico dinâmico e complexo fortemente influenciado pelas atividades antrópicas.

\subsection{O Fósforo}

Dada a grande concentração de nutrientes tais como o fósforo, os recursos aquáticos sofrem um processo de degradação que limita a atividade biológica. O fósforo é um dos principais componentes responsáveis pela eutrofização; é um elemento indispensável à manutenção da vida presente em células na forma de adenosina trifosfato (ATP), ácidos nucléicos entre outros, e cujo excesso no meio ambiente pode causar transtornos.

O fósforo ao atingir os reservatórios de água age como nutriente fazendo com que ocorra a proliferação de cianobactérias que associada a outros fatores como temperatura e tempo de retenção da água induz o ambiente aquático a desenvolver o fenômeno da eutrofização. O limite de concentração de fósforo total em ambiente lótico admitido pelas agências de monitoramento ambiental é de $100 \mathrm{mg} \mathrm{m}^{-3}$. Entre 2008 e 2011, no reservatório do Tatu localizado na bacia do ribeirão do Pinhal, no município de Limeira-SP (Figura 1), os registros das análises da concentração de fósforo apresentaram valores fora do especificado, conforme dados apresentados na Tabela 1. Verificou-se que valores iguais ou inferiores a $100 \mathrm{mg} \mathrm{m}^{-3}$ ocorreram em 14 das 24 análises (CONAMA, 2005; MARINS et al., 2007; SOUSA et al., 2010).

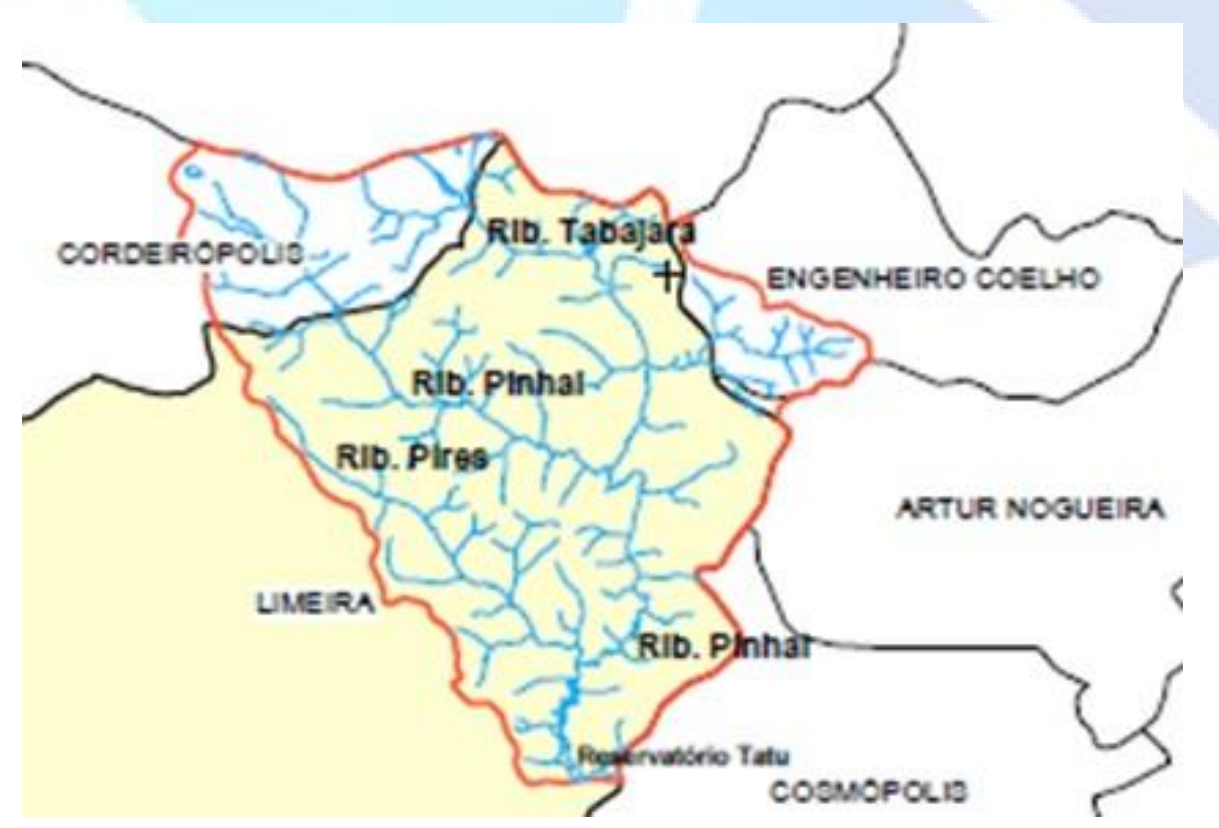

Figura 1. Localização da sub-bacia do Ribeirão do Pinhal e do reservatório do Tatu. Fonte: Mansor (2005). 
A bacia do ribeirão do Pinhal faz parte da sub-bacia do rio Jaguari, que também abastece o município de Limeira,SP, localizado no município a $22^{\circ} 33^{\prime} 52^{\prime \prime}$ de latitude sul e $47^{\circ} 24^{\prime} 17^{\prime \prime}$ de longitude oeste. Sua área é de 306,79 Km², altitudes entre 520 e $740 \mathrm{~m}$, rede hidrográfica de 257,40 $\mathrm{Km}$ e vazão em torno de $1,1 \mathrm{~m}^{3} \mathrm{~s}^{-1}$ na época da estiagem (BRANDÃO, 2001).

Tabela 1 - Concentrações de fósforo $\left(\mathrm{mg} \mathrm{m}^{-3}\right)$ entre 2008 e 2011 nas águas do reservatório do Tatu, município de Limeira, SP.

\begin{tabular}{|c|c|c|c|c|}
\hline Aporte (q) (mg m-3) & 2008 & 2009 & 2010 & 2011 \\
\hline Jan & 100 & 1.000 & 100 & 200 \\
\hline Mar & 100 & 100 & 400 & 300 \\
\hline Mai & 100 & 300 & 1.000 & 100 \\
\hline Jul & 20 & 100 & 700 & 29 \\
\hline Set & 90 & 300 & 2.000 & 20 \\
\hline Nov & 40 & 200 & 90 & 13 \\
\hline
\end{tabular}

Fonte: CETESB (a), 2008; CETESB (b), 2009; CETESB (c), 2010 CETESB (d), 2011.

Quando o elemento fósforo é carreado para os rios, ele pode permanecer no meio aquoso ou ser depositado nos sedimentos sob diferentes formas que influenciarão as características físicas, químicas e biológicas do ambiente hídrico, uma vez que podem ser novamente suspensos ou dissolvidos nesse corpo de água (MARINS et al., 2007).

Os problemas de impactos e prejuízos ambientais causados pelo desequilíbrio do ecossistema elevam os custos com o tratamento de água durante a captação para abastecimento, provocam avarias nas turbinas e nos geradores, tornam a água imprópria para consumo devido às alterações organolépticas alterando o abastecimento público de água. Muitos gêneros de cianobactérias produzem toxinas que podem ser fatais tanto para animais quanto para os humanos (SMAHA e GOBBI, 2003; FIGUEIRÊDO et al., 2007; FARIAS et al., 2009; TANIWAKI et al., 2011).

Novas pesquisas buscam técnicas cada vez mais avançadas para estudo, monitoramento e remoção de poluentes do meio aquático e, desta forma, apresenta-se a seguir uma ferramenta de análise e subsídio, baseada em procedimentos de modelagem e suporte computacional, que visa favorecer, de modo geral ou particionado, a geração de cenários que possibilitem o estudo de estratégias de gestão local e a avaliação do comportamento de poluentes num meio aquático.

A fim de minimizar os problemas decorrentes da poluição dos recursos hídricos faz-se o uso de ferramentas de gestão dos corpos de água por meio de monitoramentos da qualidade da água, bem como da caracterização do meio. Dentro deste contexto, o presente estudo expõe uma ferramenta de suporte e subsídio desenvolvida a partir de um processo de modelagem matemática e de suporte computacional que possibilita a geração de cenários e auxilia o estudo e o acompanhamento do quadro evolutivo de concentrações de poluentes na água podendo influenciar as tomadas de decisão para minimizar os impactos ou impedir que estes atinjam níveis mais elevados (ALMEIDA e PALHARINI, 2012). 


\section{MATERIAL E MÉTODOS}

Em decorrência do aumento de casos de eutrofização e dos baixos investimentos em saneamento básico busca-se formas de se avaliar o comportamento evolutivo de poluentes ao longo do tempo e do espaço. Essas informações têm por finalidade proporcionar melhores condições de avaliação e entendimento para a tomada de decisões, de modo que sejam mais seguras e eficazes em relação às estratégias de prevenção e remediação dos cenários de impactos ambiental que se estabelecem: de como prevenir ou impedir que o poluente se espalhe e/ou atinja concentrações altas, fora dos valores especificados pelos órgãos de gestão e monitoramento.

Toma-se o reservatório, conforme proposto por Meyer (2011), homeomorfo a um retângulo e desta forma, a avaliação da concentração de poluentes tem a seguinte representação (Figura 2), segundo Alves (2009).

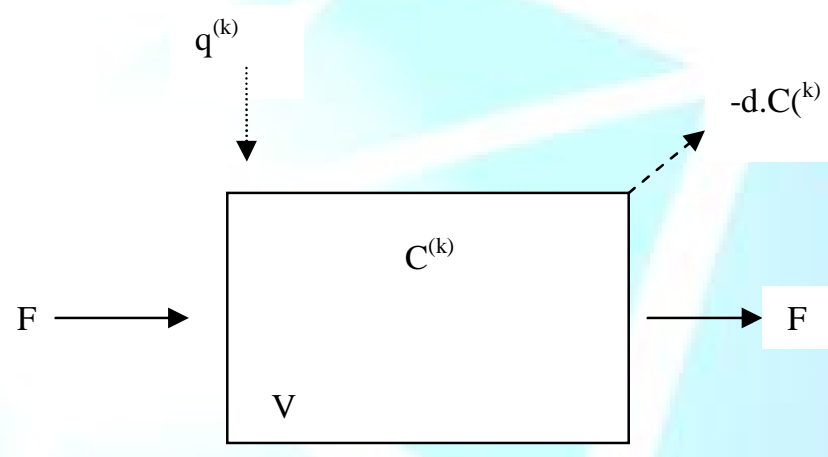

Figura 2 - Representação de represa homeomorfa à um retângulo.

A equação aplicada neste estudo para o delineamento da concentração de fósforo no reservatório é utilizada pela principal agência de proteção ambiental dos Estados Unidos, a Environmental Protection Agency (EPA) e em institutos europeus de pesquisa e foi dada por vários autores (INFORZATO, 2008; ALVES, 2009; CARNIATO, 2009; MONTOVANI, 2012).

$$
C^{k+1}=C^{k}-\frac{F}{V} C^{k}-d C^{k}+q^{k}
$$

Onde:

- $\quad d$ : representa a taxa de degradação;

- $\quad V$ : representa o volume do reservatório;

- $\quad F$ : indica o fluxo do rio que entra e que sai;

- $\quad q$ : representa o aporte de poluente lançado;

- $\quad C^{k}$ : indica a concentração do poluente no instante $k$.

O reservatório do Tatu, cuja representação aparece na Figura 3, foi dividido em 5 compartimentos, denominados compartimentos A, B, C, D e E, de modo a propiciar maior aproximação e abordagem particionada do cenário. Estes compartimentos são delineados de acordo com a batimetria local, fornecida pela Secretaria do Meio Ambiente (SMEA) da Prefeitura 
Municipal de Limeira. A referida batimetria favorece a determinação dos 5 compartimentos da represa considerados para a modelagem matemática.

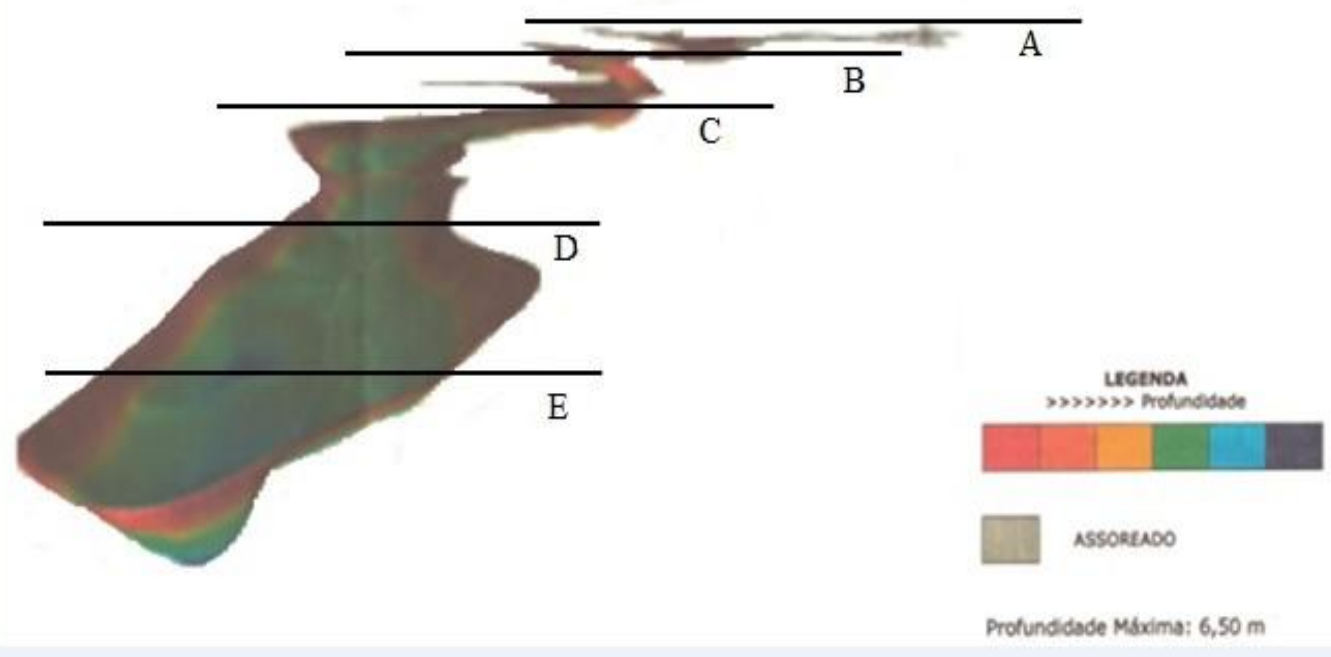

Figura 3. Batimetria do reservatório do Tatu e seus compartimentos. Fonte: SMEA, 2010.

Cada compartimento é representado por uma equação matemática com influências locais e específicas de ingresso de poluente, degradação, volume e fluxo. Para as simulações computacionais e a geração dos cenários foi desenvolvido um algoritmo computacional em ambiente MATLAB.

De acordo com SMEA (2010) e Lima (2012) os dados de campo considerados são o comprimento, volume e o fluxo da represa, aproximadamente, $5,9 \mathrm{~km} ; 1.005 .053 \mathrm{~m}^{3}$ e 4,52 $\mathrm{m}^{3} \mathrm{~s}^{-1}$, respectivamente. Ainda, de acordo com dados específicos e batimetria local fornecida pela SMEA (2010) do município, foi possível a determinação aproximada do volume e do fluxo do reservatório em cada compartimento, apresentados na Tabela 2.

Tabela 2 - Volume e fluxo de cada compartimento do reservatório do Tatu, Limeira/SP.

\begin{tabular}{c|ccccc}
\hline Compartimento & A & B & C & D & E \\
\hline Volume $\left(\mathbf{m}^{3}\right)$ & 78.163 & 93.810 & 184.080 & 224.200 & 424.800 \\
Fluxo $\left(\mathbf{m}^{3} \mathbf{d i a}^{-1}\right)$ & 30.371 & 36.451 & 71.526 & 87.115 & 165.060 \\
\hline
\end{tabular}

Para uma simulação do quadro atual da concentração de poluente no reservatório em um sentido evolutivo no tempo, 52 semanas, utilizou-se informações fornecidas pela CETESB (2008, 2009, 2010, 2011). Estas subsidiaram valores representativos, ou seja, dados estimados, que compuseram as simulações como concentração inicial, degradação e aporte. Certa interpretação de aporte foi possibilitada pelas medições do período (por qualquer tipo de ingresso: pontual ou difuso, que fosse) tomado como o valor médio obtido no período das informações, isto é, 2008 a 2011.

Como concentração inicial, embora uma parcela daquela de fósforo seja eliminada com o fluxo que escoa e outra com processos tais como a degradação, parte da concentração permanece ainda por um tempo, caracterizando o meio no início das simulações. Desta forma, a concentração 
inicial tomada correspondeu a 50\% da média do ano de 2011. Como degradação considerou-se, hipoteticamente, os valores $0 \%, 1 \%, 5 \%$ e $10 \%$. Tal fenômeno vem sendo foco de pesquisas em andamento.

O ingresso de poluente na represa levou em consideração o período de maior incidência de chuvas que ocorre entre setembro e fevereiro e o período de menor incidência que ocorre entre março e agosto e influenciam diretamente a entrada de poluente por fenômenos à deriva, sendo modelado a partir de uma função oscilatória dada por: $q(n)=\bar{q}+\Delta q \leqslant \operatorname{sen}\left(\frac{n \pi}{26}\right)$ onde $\bar{q}$ representa o aporte médio de poluente na represa, $\Delta q$ representa a taxa de variação do aporte e $n$ o número de semanas.

\section{RESULTADOS E DISCUSSÃO}

Em cada cenário gerado foram obtidas 5 curvas. Cada uma delas representou a concentração de fósforo em cada compartimento do reservatório. O compartimento A, menor em fluxo e volume, representou a primeira porção à montante do reservatório - o início do reservatório e a entrada das águas na bacia do ribeirão do Pinhal - seguido pelos compartimentos subsequentes até o compartimento $\mathrm{E}$, que foi o último deles, maior em volume e fluxo, próximo à saída das águas represadas para o ponto de captação.

Por meio dos cenários gerados, observou-se que o sistema apresentou a máxima concentração de fósforo no compartimento E, na degradação de $0 \%$, Figura 4 (a). Verificou-se que à medida que o potencial de degradação no meio aumentou, a concentração final do poluente diminuiu. O cenário de menor concentração de fósforo se deu com a degradação de $10 \%$ (Figura 4 d).

Uma análise dos cenários em relação ao número de semanas em que a concentração de poluentes se encontrou dentro do especificado mostrou que no cenário (a) a concentração de poluentes permaneceu dentro do limite máximo estabelecido entre as semanas 33 e 53 . No cenário (b) a concentração ficou dentro do padrão estabelecido entre as semanas 32 e 53; no cenário (c) o poluente atendeu o especificado entre as semanas 31 e 53 ; e no cenário (d) entre as semanas 30 e 53.

Em relação aos compartimentos, observou-se que em todos os cenários, em determinadas semanas, os compartimentos A e B apresentaram concentração de fósforo $\leq 100 \mathrm{mg} \mathrm{m}^{-3}$. O cenário $\mathrm{C}$ apresentou o poluente dentro do limite máximo permitido, porém em um período inferior aos compartimentos A e B. Os compartimentos D e E apresentaram concentração de fósforo dentro do estabelecido apenas nos cenários (c) e (d), sendo que o compartimento E caracterizou-se, em detrimento dos demais, como o compartimento de maior concentração de fósforo. 


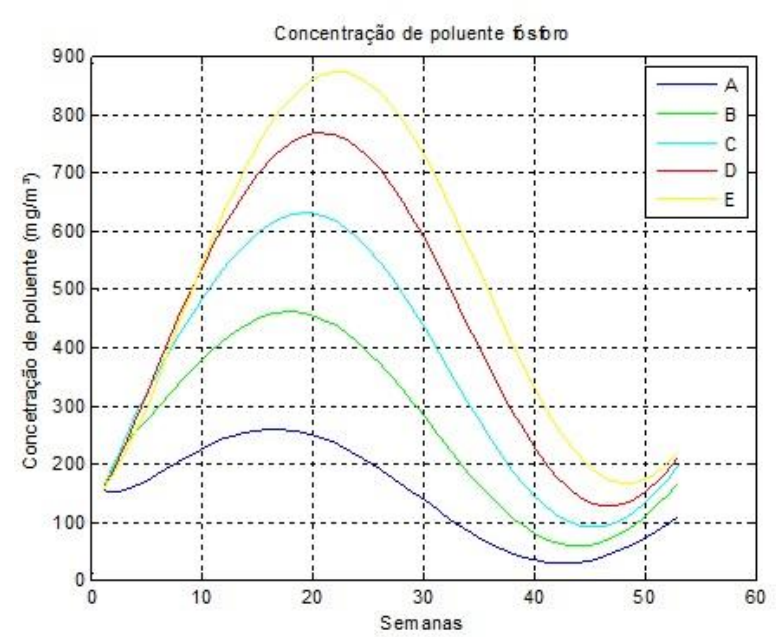

(a) Degradação de $0 \%$.

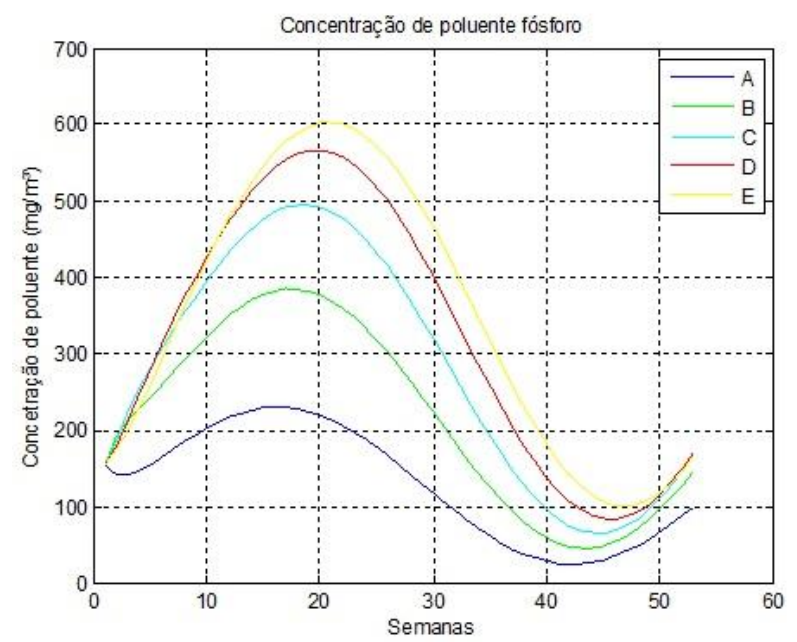

(c) Degradação de $5 \%$.

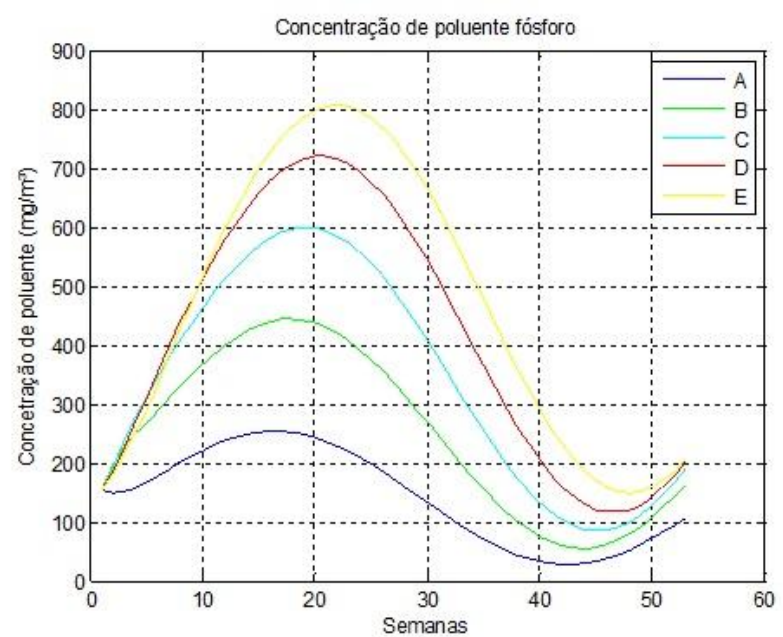

(b) Degradação de $1 \%$.

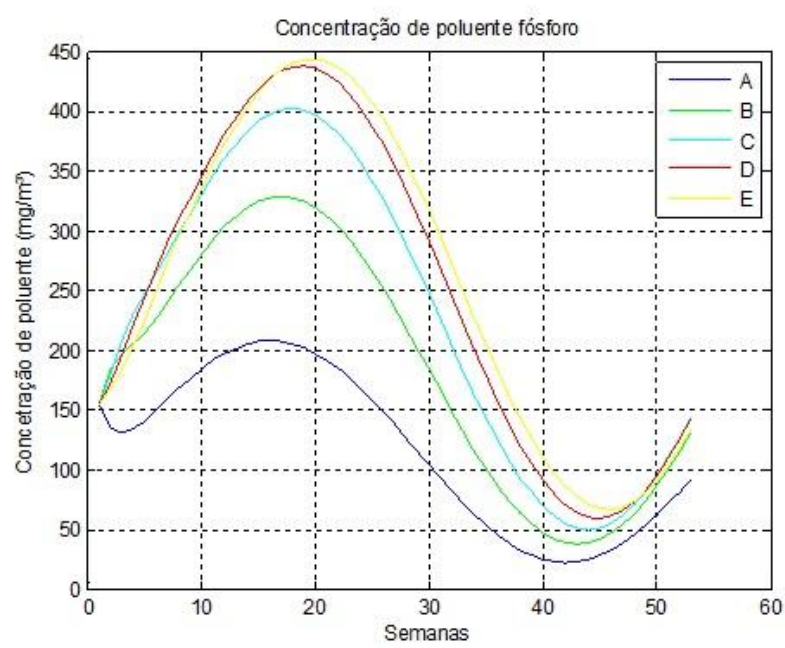

(d) Degradação de $10 \%$.

Figura 4 - Simulação para quatro valores de degradação e aporte variável.

A degradação que ocorreu por fenômenos tais como a biodegradação, a fotodegradação, a degradação por ações mecânicas, entre outros fenômenos, representou a eliminação do poluente do meio e, como pode ser observado, quanto maior o potencial de degradação na água, menor a concentração do poluente.

Com os aportes e as respectivas taxas de degradação, a concentração de fósforo, na maioria dos cenários, apresentou-se com valores altos quando comparados à quantidade máxima estabelecida pelos órgãos governamentais ficando apenas durante algumas semanas dentro do limite máximo permitido, ou seja, apresentou concentração igual ou inferior a $100 \mathrm{mg} \mathrm{m}^{-3}$.

Buscou-se com o aporte modelado através de uma função oscilatória, representar ingresso de poluentes ao longo do ano, tanto em períodos mais chuvosos quanto em períodos mais secos. Nos períodos mais chuvosos com fenômenos de lixiviação e maiores carreamentos de nutrientes para a água (decorrentes de aplicação de fertilizantes, entre outros produtos químicos no solo) maior foi a concentração do fósforo em detrimento aos períodos menos chuvosos, com menor ingresso de poluente à deriva.

Observou-se que com esta ferramenta de modelagem é possível fazer a gestão de bacias hidrográficas em relação à quantidade e a dispersão do poluente, tendo em vista uma adequada 
manutenção do corpo de água e a busca de soluções específicas para problemas até então desconhecidos.

A modelagem matemática pode ser utilizada para subsidiar as tomadas de decisões na gestão dos recursos hídricos, uma vez que por meio dos resultados e cenários obtidos é possível a elaboração de relatórios, projetos, pareceres e laudos, assim o impacto de um poluente sobre o corpo hídrico pode ser administrado, remediado ou até mesmo evitado.

\section{CONCLUSÕES}

Neste trabalho utilizou-se um modelo simples baseado em um sistema de equações de diferenças para modelar a concentração de fósforo em um sistema de reservatório. O modelo, embora utilizado para verificar o comportamento do fósforo, mostrou-se uma ferramenta eficaz para o estudo de impacto ambiental em recursos aquáticos favorecendo além de modelagens, a análise e a compreensão do comportamento de poluentes presentes nos corpos aquáticos, inclusive os de abastecimento público.

Observou-se nos cenários obtidos, que este modelo forneceu dados que podem subsidiar discussões e tomada de decisão. O modelo pode ser aprimorado com mais variações tais como a de volume e de fluxo ao longo do ano e com dados mais representativos de diversos poluentes que se apresentem alterados em recursos aquáticos e ou se mostrem de grande relevância para o ecossistema e/ou para fins de abastecimento.

No tocante ao fósforo, constatou-se que os corpos de água necessitam de monitoramento constante de verificação dos índices do componente, tendo-se em vista os diversos problemas de impacto ambiental decorrentes da presença em excesso de elementos fosfatados. Atrelada a isso, torna-se necessária a implantação de políticas e gestão que resultem na diminuição de aplicação de elementos desta natureza que, além de provocar alterações nos ecossistemas aquáticos, corroboram para a formação de um sistema de qualidade comprometida.

\section{REFERÊNCIAS}

ALEXANDRE, D.M.B.; ANDRADE, E.M.; LOPES, F.B.; PALÁCIO, H.A.Q.; FERREIRA, A.C.S. The water quality investigation using GIS and multivariable analysis in a semiarid region reservoir. Revista Ciência Agronômica, Fortaleza, v. 41, n. 4, p. 554-561, 2010.

ALMEIDA, L.M.W.; PALHARINI, B.N. Os "Mundos da Matemática" em atividades de modelagem matemática. Bolema, Rio Claro, v. 26, n. 43, p. 907-934, 2012.

ALVES, L.F.B. Modelagens matemáticas para simulações computacionais de impacto ambiental no rio Balsas. 2009. 74 f. Dissertação (Mestrado em Matemática) - Instituto de Matemática, Estatística e Computação Científica, Universidade Estadual de Campinas, 2009.

ANDRADE, D.P.; PASCHOAL, L.R.P.; SÁ, O.R.; FRANCA, N. Water quality assessment of fifthorder tributaries of the reservoir at the Marechal Mascarenhas de Morais Hydroelectric Power Station in the Rio Grande watershed (State of Minas Gerais, Brazil). Acta Limnologica Brasiliensia, Rio Claro, v. 24, n. 3, p. 326-337, 2012.

BEGHELLI, F.G.S.; SANTOS, A.C.A.; URSO-GUIMARÃES, M.V.; CALIJURI, M.C. Relationship between space distribution of the benthic macroinvertebrates community and trophic 
state in a Neotropical reservoir (Itupararanga, Brazil). Biota Neotrópica, Campinas, v. 12, n. 4, p. $1-11,2012$.

BRANDÃO, D. Risco de degradação dos recursos hídricos na bacia do Ribeirão Pinhal Limeira (SP): uma proposta metodológica. 2001. 99 f. Dissertação (Mestrado em Engenharia Agrícola) - Faculdade de Engenharia Agrícola, Universidade Estadual de Campinas, Campinas, 2001. Disponível em: <http://www.bibliotecadigital.unicamp.br/document/?code=vtls000235348>. Acesso em: 15 jun. 2013.

BUFON, A.G.M.; LANDIM, P.M.B. Análise da qualidade da água por metodologia estatística multivariada na represa Velha (CEPTA/IBAMA/PIRASSUNUNGA/SP). Holos Environment, Rio Claro, v. 7, n. 1, p. 42-59, 2007.

CARNIATO, N.K.S.M. Comportamento evolutivo de uma pluma superficial de poluente na bacia hidrográfica do rio Mogi Guaçu. 2010. 95 f. Dissertação (Mestrado em Engenharia Elétrica) - Faculdade de Engenharia Elétrica e de Computação, Universidade Estadual de Campinas, Campinas, 2010.

CETESB (a). Companhia Ambiental do Estado de São Paulo. Apêndice D - resultados dos parâmetros e indicadores de qualidade das águas 2008. 2008. Disponível em: <http://www.cetesb.sp.gov.br/agua/aguas-superficiais/35-publicacoes-/-relatorios>. Acesso em: 12 fev. 2013.

CETESB (b). Companhia Ambiental do Estado de São Paulo. Resultados de qualidade de água por UGRHI 2009. 2009. Disponível em: <http://www.cetesb.sp.gov.br/agua/aguassuperficiais/35-publicacoes-/-relatorios>. Acesso em: 12 fev. 2013.

CETESB (c). Companhia Ambiental do Estado de São Paulo. Dados das variáveis de qualidade das águas (doce, salobra e salina) e dos sedimentos 2010. 2010. Disponível em:

<http://www.cetesb.sp.gov.br/agua/aguas-superficiais/35-publicacoes-/-relatorios>. Acesso em: 12 fev. 2013.

CETESB (d). Companhia Ambiental do Estado de São Paulo. Dados das variáveis de qualidade das águas (doce, salobra e salina) e dos sedimentos 2011. 2011. Disponível em:

<http://www.cetesb.sp.gov.br/agua/aguas-superficiais/35-publicacoes-/-relatorios>. Acesso em: 12 fev. 2013.

CONAMA. Conselho Nacional do Meio Ambiente. 2005. Dispõe sobre a classificação dos corpos de água e diretrizes ambientais para o seu enquadramento, bem como estabelece as condições e padrões de lançamento de efluentes, e dá outras providências. Resolução n. 357, de 17 de março de 2005. Disponível em: <http://www.mma.gov.br/port/conama/res/res05/res35705.pdf> Acesso em: 05 mai. 2013.

DELLAMATRICE, P.M.; COSTA, L.S.; SOUSA, M.V.; AAÚJO, R.S. Avaliação da toxicidade da água e sedimento do açude Jaburu (Ceará - BR) na região do semi-árido. Holos Environment, Rio Claro, v. 12, n. 2, p. 168-178. 2012.

FARIAS, M.M.M.W.E.C.; BELFORT, C.F.N.L.A.L.; BARBOSA, I.M.B.R.; CARVALHO, V.S. Vulnerabilidade à eutrofização de reservatórios a partir da estimativa de cargas poluentes. In: 
CONGRESSO DE PESQUISA E INOVAÇÃO DA REDE NORTE NORDESTE DE EDUCAÇÃO TECNOLÓGICA - CONNEPI, 4, 2009, Belém. Anais... Belém, 2009. 1 CD.

FIGUEIRÊDO, M.C.B.; TEIXEIRA, A.S.; ARAÚJO, L.F.P.; ROSA, M.F.; PAULINO, W.D.; MOTA, S.; ARAÚJO, J.C. Avaliação da vulnerabilidade ambiental de reservatórios à eutrofização. Engenharia Sanitária e Ambiental, Rio de Janeiro, v. 12, n. 4, p. 399-409, 2007.

FRAGOSO JUNIOR, C.R.; TUCCI, C.E.M.; COLLISCHONN, W; MARQUES, D.M.L.M. Simulação de eutrofizaçãoem lagos rasos: I - modelo e precisão numérica. Revista Brasileira de Recursos Hídricos, Porto Alegre, v. 12, n. 4, p. 23-35, 2007.

INFORZATO, N. F. Dispersão de poluentes num sistema ar-água: modelagem matemática, aproximação numérica e simulação computacional. 2008. 109 f. Tese (Doutorado em Matemática Aplicada) - Instituto de Matemática, Estatística e Computação Gráfica, Universidade Estadual de Campinas, Campinas, 2008. Disponível em:

<http://cutter.unicamp.br/document/?code=vtls000441185>. Acesso em: 25 fev. 2013

JORGENSEN, S.; TUNDISI, J.G.; TUNDISI, T.M. 2012. Handbook of inland aquatic ecosystem management. CRC Press, Boca Raton, FL, 430 p.

LIMA, H. Reservatório do Tatu [mensagem pessoal]. Mensagem recebida por <camilamontovani@yahoo.com.br> em 08 mai. 2012.

MANSOR, M. T. C. Potencial de poluição de águas superficiais por fontes não pontuais de fósforo na bacia hidrográfica do Ribeirão do Pinhal, Limeira - SP. 2005. 189 f. Tese (Doutorado em Engenharia Agrícola, área de concentração Água e Solo) - Faculdade de Engenharia Agrícola, Universidade Estadual de Campinas, Campinas, 2005. Disponível em:

<http://www.lapa.ufscar.br/bdgaam/agua/Polui\%E7\%E3o/Mansor.pdf>. Acesso em: 23 ago. 2013.

MANSOR, M.T.C.; TEIXEIRA FILHO, J.; ROSTON, D.M. Avaliação preliminar das cargas difusas de origem rural, em uma sub-bacia do rio Jaguari, SP. Revista Brasileira de Engenharia Agrícola e Ambiental, Campina Grande, v. 10, n. 3, p. 715-723. 2006. Disponível em: <www.scielo.br/pdf/rbeaa/v10n3/v10n3a26.pdf>. Acesso em: 20 mai. 2013.

MARINS, R.V.; PAULA FILHO, F.J.; ROCHA, C.A.S. Geoquímica de fósforo como indicadora da qualidade ambiental e dos processos estuarinos do rio Jaguaribe - costa nordeste oriental brasileira. Química Nova, São Paulo, v. 30, n. 5, p. 1208-1214, 2007.

MEYER, J. F. C. A.; CALDEIRA, A. D.; MALHEIROS, A. P. S. Modelagem em Educação Matemática. Belo Horizonte: Autêntica Editora, Coleção de Tendências em Educação Matemática, 2011.

MONTOVANI, C.P. Presença de fósforo e modelagem de seu comportamento evolutivo no reservatório do Tatu. 2012. 106 f. Dissertação (Mestrado em Tecnologia) - Faculdade de Tecnologia, Universidade Estadual de Campinas, Campinas, 2011.

POLETTI, E.C.C. Dispersão de poluente em sistema de reservatório: modelagem matemática e simulação computacional utilizando-se aproximação numérica e lógica Fuzzy. 105 f. Tese 
(Doutorado em Engenharia Elétrica) - Faculdade de Engenharia Elétrica e de Computação Científica - Universidade Estadual de Campinas, Campinas, 2009.

SMAHA, L.; GOBBI, M.F. Implementação de um modelo para similar a eutrofização do reservatório do Passaúna - Curitiba - PR. Revista Brasileira de Recursos Hídricos, Porto Alegre, v. 8 , n. 3, p. 59-69, 2003.

SMEA - SECRETARIA DE MEIO AMBIENTE - Prefeitura Municipal de Limeira. Batimetria Represa Tatu. 2010.

SOUSA, A.C.S.; CARDOSO, C.E.; FRAGUAS NETO, M.R. Determinação da concentração de fosfato em amostras de detergente em pó utilizando detecção titulométrica. Revista Eletrônica TECCEN, Vassouras, v. 3, n. 4, p. 19-28, 2010.

TANIWAKI, R.H.; ROSA, A.H.; CALIJURI, M.C.C.; CARLOS, V.M. Variação especial do grau de trofia e da biomassa fitoplanctônica no reservatório de Itupararanga (São Paulo, Brasil). Holos Environment, Rio Claro, v. 11, n. 2, p. 170-179, 2011. 